\title{
Síndrome X fráxil, os inicios da comunicación e a linguaxe
}

\section{Fragile X syndrome, beginning of Communication and Language}

\author{
Beatriz López González, María Lorena Pernas Cortiñas \\ Asociación de pais de nenos e persoas con discapacidade das mariñas coruñesas (DISMACOR). Culleredo. A Coruña. España. \\ Universidade da Coruña. España.
}

\begin{abstract}
Resumo
A síndrome $X$ fráxil é un trastorno xenético debido á mutación dun xen que produce unha proteína necesaria para o desenvolvemento cerebral. No presente traballo exponse unha intervención logopédica realizada cun cativo de seis anos con Síndrome X fráxil que carece de linguaxe e estratexias de comunicación. Pártese dunha avaliación inicial do desenvolvemento, posteriormente impleméntase un programa de intervención ao longo de doce meses para rematar cunha avaliación final. Os resultados sinalan que este tipo de intervencións aumentan as posibilidades de comprensión da contorna mellorando a adquisición de habilidades comunicativas.
\end{abstract}

Palabras chave: Síndrome X-fráxil, logopedia, S.A.A.C., e intervención en contornas naturais.

\begin{abstract}
Fragile $\mathrm{X}$ syndrome is a genetic disorder due to mutilation of a gene that produces a protein, for its incidence is considered the leading cause of hereditary mental functional diversity. This paper presents a speech therapy intervention performed with a six years old boy with fragile $\mathrm{X}$ syndrome lacking languages and communication strategies One starts with initial assessment which includes the state of development of the child. Below are designs and implements an intervention program over twelve months, to end with a final evaluation in which the progress made over this period are identified. The results indicate that this type of intervention increases the chances of understanding the environment by improving the acquisition of communication skills.
\end{abstract}

Keywords: Fragile X syndrome, speech and languaje theray, Alternative and Augmentative Communication (AAC), intervention in natural environments.

\section{Introducción}

A síndrome X Fráxil tamén chamada "Síndrome de Martin-Bell" e a causa máis frecuente de trastorno por déficit intelectual hereditario. É un trastorno xenético debido a mutación dun xen (FMR1) ligado o cromosoma $\mathrm{X}$ causando a ausencia dunha proteína (FMRP). E dicir, debido a mutación, o xen se inactiva e non pode sintetizar dita proteína. (Laffon e Pásaro, 2012).

Esta síndrome afecta tanto a homes como a mulleres, inda que éstas en menor grado, xa que o ter dous cromosomas $\mathrm{X}$ o segundo as protexe. Inda así, todas elas serán portadoras puidendo transmitir a alteración os fillos xenéticamente. No caso dos homes, e maior a afectación, xa que solo presentan un cromosoma $\mathrm{X}$ susceptible de sufrir a mutación. Neste caso, tódolos homes portadores transmitirán necesariamente a alteración as súas fillas .(Aguado, 2006).

A prevalencia e de 1/4000 homes e de 1/6000 mulleres, en tódolos grupos étnicos por igual. A frecuencia de mulleres portadores é de $1 / 600$, e éstas non están afectadas habitualmente. (Laffon e Pásaro, 2012).

\section{Características físicas}

* Cara alargada con frente ampla e queixo prominente.

*Orellas grandes e saíntes (como de soplillo).

*Hiperlaxitude das articulacións.

*Macroorquidismo en varóns.

*Estrabismo.

*Soplo cardíaco.

*Pel fina.

(Laffono e Pásarro, 2012).

\section{Caraterísticas psíquicas}

As características de conducta máis frecuentes nos varóns son: hiperactividade, trastornos da atención, timidez extrema, evitación da mirada, linguaxe repetitivo, estereotipias con aleteos, morder as mans, angustia, hipersesibilidade os estímulos, resistencia os cambios.... Nas mulleres: angustia, timidez e dificultades nas áreas das matemáticas. O trastorno por discapacidade intelectual depende da afectación que teña o individuo puidendo ser dende leve a moderada.

\section{Características da linguaxe e a comunicación}

As persoas afectadas con X Fráxil se caracterizan por certos rasgos coma retraso mental leve ou moderado, retraso na aparición da linguaxe, hiperactividade con déficit de atención, evitación da mirada e comportamento de tipo autista. (Laffon e Pásaro, 2012).

Un porcentaxe de nenos con SXF teñen un comportamento que recorda os nenos con TEA. Os 
rasgos máis habituais son o contacto ocular escaso, a defensa táctil, perseveración na linguaxe e nos actos, o aleteo, mordeduras.... Sen embargo a diferencia con respecto os nenos con TEA e que mostran interés por relacionarse socialmente.

Os nenos con síndrome X Fráxil, presentan un patrón da fala moi rápido, perseverante e repetitivo. Así coma unha fala impulsiva e con bastantes fluctuacións no ritmo. Tamén se caracterizan por abundantes ecolalias e cambios inusuais da voz como a subida do tono provocando unha prosodia inadecuada. Estos problemas na fala dificultan a intelixibilidade de ésta.

En relación a linguaxe, mostran unha estructuración morfosintáctica pobre,e dificultades pragmáticas relacionadas coa evitación social, ansiedade, a resistencia á adaptación os cambios e acontecementos repentinos, dificultades en manter un tema de conversación senón é do seu interese, e polo contrario poden chegar a obsesionarse con determinados temas e resultarles complexo falar doutra cousa e dificultades para manter o turno da palabra.

Durante os primeiros anos de vida se evidencia especialmente un nivel de comprensión da linguaxe bastante por encima da capacidade de expresión. A comprensión do vocabulario é aceptable, pero a medida que aumenta a complexidade dos enunciados poden surxir dificultades na comprensión.

\section{Intervencións en contornas naturais}

A intervención en persoas con diversidade funcional evolucionou ao longo dos últimos anos. Algúns dos programas que inicialmente impartía persoal experto en centros especializados, trasládanse agora ao fogar, aos ambientes naturais en que vive o/a neno/a, de tal xeito que a familia é a protagonista executora do programa no cal recibe a axuda dos/as profesionais (Troncoso Hermosa, 1994, López-González, 2011). Da evolución destes programas falaremos a continuación.

Según indica Grácia (1999), durante os anos 70 a maior parte das investigacións e intervencións (...) levadas a cabo en Estados Unidos seguían un enfoque conductista (Fey, 1986; Warren e Yoder, 1994). Pero será a partir dos anos 80 cando se produza un cambio. Este cambio de rumbo estivo acompañado, ademais, por un movemento conceptual dende o conductismo mecanicista de Skinner cara modelos contextualistas, nos que se daba unha importancia fundamental ao contexto inmediato á hora de determinar a forma e a función de calquer actividade (Grácia, 1999; Odom e Haring, 1994). O cambio máis importante que se introduce cos enfoques naturalistas ten que ver co feito de que nestes casos a intervención se leva a cabo en contextos nos que o neno/a pasa unha parte importante do día, como a o fogar. Por tánto falaríase da importancia das intervencións en contornas naturais.

Segundo autores como Sánchez Cano e Bonals (2007) o enfoque naturalista, en contraposición aos estudos de laboratorio, tende a buscar un tipo de intervención no contexto natural do desenvolvemento e aprendizaxe e seguir un proceso natural de adquisición interactuando cos adultos. Tal e como sinala Del Río (1997) a intervención naturalista se leva a cabo en contextos cotidianos, naturais, ou ben fai intervir a adultos que están moitas horas en contacto cotidiano cos neno/as, sexan pais ou mestres, ou se isto non é posíbell, reproduce as características interactivas destos contextos e interlocurores cotidianos. Estas peculiaridades a diferencian da intervención/instrucción directa e aumentan as posibilidiades de xeralización (Rondal, 1983) que, como se sabe, é un dos problemas cos que en moitas ocasións os profesionais se atopan a hora de transferir os logros acadados en sesións tradicionais á contorna natural dos cativos. Ademais a intervención naturalista e interactiva ten unha especial utilidades social xa que, ao maximizar o potencial optimizador dos axentes naturais do desenvolvemento diminue costes (...).

\section{Método}

\section{Participantes}

O suxeito é un neno diagnosticado de Síndrome de X Fráxil, que na actualidade ten 6 anos e 6 meses. Os seus pais están divorciados. A súa contorna familiar habitual está constituída pola súa nai, un irmán de 8 anos, os seu avó, unha avóa con Alzheimer en estado avanzado e o seu tío materno, que o atendería tamén en múltiples ocasións.

$\mathrm{Na}$ actualidade o cativo segue unha escolarización combinada. Acude dous días á semana ao centro ordinario onde está escolarizado en $3^{\circ}$ de Educación Infantil. Nos inicios carece de linguaxe, imitación, verbalizacións... Mostrando moitos problemas de comportamento (xirar obxectos, aleteos, valanceo, falta de contacto visual, conductas obsesivas...). Carece de control de esfínteres. Mostra dificultades para alimentación e introducción de novos alimentos. Orientado por rutinas e con grandes dificultades cos cambios na contorna.

\section{Obxectivos}

O obxectivo fundamental da intervención é coñecer a repercusión do emprego combinado de estratexias de intervención en contorna natural e tamén noutras estructuradas.

Os obxectivos específicos son :

- Compensar os problemas de incomunicación.

- Mellorar e desenvolver a expresión verbal e a linguaxe.

- Aumentar o número de vocalizacións e expresións.

- Implementar o bimodal como axuda para a comunicación.

- Mellorar a comprensión da contorna. 
- Saber expresar as necesidades e desexos próprios.

- Propiciar ferramentas para facerse entender com familiares, coñecidos e descoñecidos.

\section{Procedemento}

Para realizar o programa efectúanse intervencións individuais cunha duración de unha hora dúas veces á semana ao longo de 8 meses. E tres intervencións semanais ao longo de catro meses.

Efectuase unha avaliación inicial e final do cativo empregando a Escala Observacional do deselvolvemento (Secadas, 1992). Na avaliación final tamén se inclue o Test de vocabulario en Imaxes Peabody (Dunn, 1959).

\section{O programa de intervención.}

O programa emprega unha intervención en contorna natural recorrendo a situacións cotidianas (na casa, xardín, supermercado, campamentos...) onde se traballa para facilitar a interación coas persoas. Este proceso completouse cun programa de intervención en contorna controlada e outro programa de intervención indirecto centrado no asesoramento e formación da familia.

Este programa conta coas seguintes actividades tipo:

- Adquisición de vocabulario en situacións reais. Por exemplo: Coñecer as froitas nun supermercado.

- Comprensión da contorna realizando tomas de decisión sobre a onde ir. Por exemplo: Sinalar en imaxes ou realizar signos para indicar se quere ir ao parque, praia, biblioteca...

- Expresión de desexos mediante verbalizacións. Por exemplo: Solicitar o alimento que desexa na cocina emitindo, pan, chocolate, galleta, gusanitos...

- Propiciar vocalizacións a través de xogos co corpo apoiados co irmán.

- Propiciar a emisión de sons a través de movementos do corpo por exemplo saltando nunha cama elástica nun parque ou movéndose ao longo dun columpio.

- Facilitar estratexias á familia para que saiba como interaccionar co neno.

No programa facilítase a comunicación multisensorial en todas as actividades favorecendo a expresión de emocións básicas e preferencias a través de diferentes ferramentas que propician a comprensión de intencións comunicativas. Ademais trátase de que se exploren as posibilidades comunicativas do propio corpo, dos obxectos así como a iniciación aos movementos, xestos e ritmos.

Posteriormente e tras unhas 112 sesións dunha hora efectuadas en grupos reducidos, procédese a unha avaliación final do suxeito.

\section{Resultados}

O emprego da intervención en contornas naturais como ferramenta nas persoas con diversidade funcional permite acadar avances en diferentes áreas do desenvolvemento. A continuación recóllese nunha táboa resultar obtidos neste proceso.

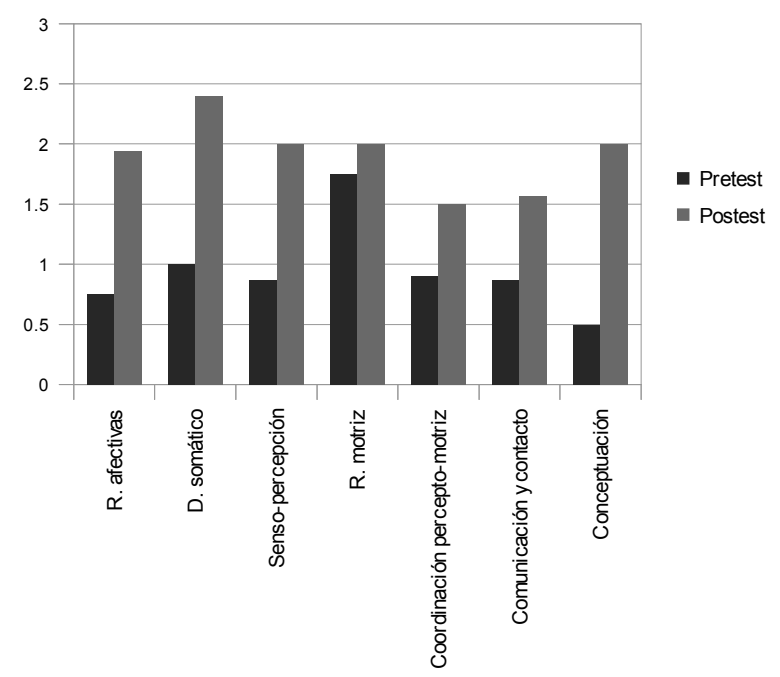

Figura 1. Puntuacións recollidas na avaliación final e final do programa.

Os resultados obtidos no Test de vocabulario en Imaxes Peabody mostran unha puntuación de 3 anos e 3 meses. Mostrando que aínda que o nivel de expresión aínda non está moi avanzado a comprensión da contorna e moi superior do agardado.

Tras o programa de intervención o cativo pasou a emitir diferentes tipos de sons vogálicos e algúns consonánticos aparecento palabras como: huevo, hola, así, agua, dame, pan... Adquiríronse varios signos como (casa, comer, beber, porta, ordenador, chaves, xogar, rúa, rematou, pan, chocolate, galleta, ascensor, traballar...)

$\mathrm{Na}$ valoración cualitativa do programa a familia comenta que os aspectos máis valorados son as relacionados co comportamento e a disminución de conductas disruptivas a raíz de contar con medios que permiten a comunicación co neno con diversidade funcional. Cando o cativo quere algo indicao e fai verbalizacións que permiten que os achegados o entendan. Tendo importantes repercusións na satisfacción e calidade de vida de todos.

\section{Discusión e conclusións}

As novas tendencias en investigación céntranse en procurar que as persoas con diversidade funcional 
podan desenvolverse en contornas normalizadoras onde podan aprender ofrecéndolles os apoios necesarios. A aprendizaxe vóltase máis sinxela e motivante cando o que se emprega son contornas naturais nas que os suxeitos se desenvolven e xeralizan os resultados dun modo máis axil e con menor esforzo. As persoas aprenden do que lles rodea: nas súas casas, cos seus irmáns, cos seus xoguetes... aprenden a pedir o que desexan comer nas súas cocinas e a pedir ir de paseo nas entradas das súas casas. Aprenden que é a praia metendo os pes na area e mollándose no mar. Este tipo de actividades son moi motivantes e facilitan a aprendizaxe con menor esforzo que con outros recursos máis elaborados.

\section{Referencias}

Aguado, G. (2006). Dificultades de lenguaje relacionadas con el retraso mental. En J.L.Galllego (Ed.), Enciclopedia temática de logopedia (354-362). Málaga, España: Ediciones Aljibe S.L.

Artigas-Pallarés, J., e Narbona J. (2011) Trastornos del neurodesarrollo. Madrid: Editorial Viguera

Bueno, M. (2012). El sindrome X frágil: la historia interminable. Zaragoza: Editorial Real academia de medicina.

Brignani, E. V. (2007). Plan piloto de apoyo familiar para familias con hijos afectado con el síndrome X Frágil. SXF. Revista periódica de la asociación X Frágil del País Vasco, número 7, Página 4- Eduardo V. Brignani (Mayo 2011).

Del Río, M. J. (Comp). (1997). Interacción y desarrollo del lenguaje en personas con necesidades especiales. Barcelona: MartínezRoca.

Fey, M. E. (1986). Language intervention with young children. Columbus, Ohio: Allyn y Bacon.

García, K. (2012). Cómo podemos hacer más fácil el aprendizaje de un niño/a con SXF.
SXF. Revista periódica de la asociación $X$ Frágil del País Vasco, número 20, página 12.

Gracia, E. (1999). Apoyo y ayuda mutua en familias en situación de riesgo. Boletín De Ayuda Mutua y Salud. Comunidad De Madrid, 9, 13-20.

Laffon, B. e Pásaro, E. (2012). Bases congénitas de las alteraciones del lenguaje (293-321). España: Bubok

López-González, B. (2011). A intervención psicoeducativa e a calidade de vida familiar de persoas con diversidade funcional: boas prácticas e tecnoloxías da Comunicación e Información. Tese de doutoramento non publicada. Universidade da Coruña.

Odom e Haring (1994). Contextualism and applied behavior analysis: Implications for early- childhood education for children with disabilities. Behavior analysis in education. En Gardner et al (Eds.). Brooks/Cole Publishing Co.

Rondal, J. A. (1983). L'interaction adulteenfant et la construction du langage. Liège, Mardaga.

Sánchez-Cano, M. e Bonals, J. (coords) (2007). Manual de asesoramiento psicopedagógico. Barcelona: Graó

Troncoso Hermosa, M. V. (1994). Programas de estimulación Temprana. En S. Molina García, (Dir.), Bases Psicopedagógicas de la Educación Especial. Alcoy: Marfil.

Warren, F. e Yoden, P. J. (1996). Enhancing Communication and Language Development in Young Children With Developmental delays and disorders. Peabody journal of education, 71 (49), 118-132.

Wilson, P. e O`Connor, R. (2011)., Capitulo, 11. Terapia del habla y del lenguaje (Logopedia). Trastornos del neurodesarrollo, Páginas 105107, (2011). Madrid: Editorial Viguera. 